\title{
PREVALENCE OF ADENOMYOSIS IN HYSTERECTOMY SPECIMENS PERFORMED AT A TERTIARY HOSPITAL OF KATHMANDU, NEPAL
}

\author{
Pande $K,{ }^{1}$ Koirala $S,{ }^{1}$ Giri $A^{2}$
}

${ }^{1}$ Department of Pathology, ${ }^{2}$ Department of Obstetrics and Gynecology, Nepal Medical College and Teaching Hospital, Attarkhel, Gokarneshwor-8, Kathmandu, Nepal

\begin{abstract}
Adenomyosis is a common condition, detected in $15-30 \%$ of hysterectomy specimens. It is characterized by the presence of endometrial glands and stroma within the myometrium. The data regarding incidence or incidental finding of adenomyosis in hysterectomy specimen is lacking despite this condition being common and bearing serious implications in symptomatology as well as in infertility. Adenomyosis can be incidental finding in hysterectomy done for other gynecologic pathology as well. Hence, this present study has established the prevalence of adenomyosis as well as it's association with other uterine pathology in routine hysterectomy specimens. This was a cross sectional study conducted at Nepal Medical College and Teaching Hospital (NMCTH), Kathmandu for a duration of one year (March 2019 to February 2020). Total of 154 hysterectomies were included in the study, out of which 37 cases showed adenomyosis. The prevalence of adenomyosis was $24 \%$. The age group for adenomyosis ranged from 36 years to 52 years with the mean age of $44 \pm 4.4$ years. The most common pathology other than adenomyosis was leiomyoma (19 cases) followed by two cases of endometriotic cyst, two cases of endometrial polyp, one case of high grade squamous intraepithelial lesion (HSIL), one case of hyperplasia of endometrium with atypia, and one case of serous cyst adenoma of ovary. Thus this study showed that the prevalence of adenomyosis was $24 \%$ and was seen higher in the age group of 35-50 years. The most frequent co-pathology in these adenomyosis cases was leiomyoma.
\end{abstract}

\section{KEYWORDS}

Adenomyosis, hysterectomy,

leiomyoma

\section{CORRESPONDING AUTHOR}

Dr Kricha Pande,

Assistant Professor

Department of Pathology,

Nepal Medical College and Teaching Hospital

Attarkhel, Gokarneshwor-8, Kathmandu, Nepal

Email: krichapande@gmail.com

Orcid ID: https://orcid.org/0000-0002-9303-831X

DOI: https://doi.org/10.3126/nmcj.v22i3.32629 


\section{INTRODUCTION}

Adenomyosis is a common condition, detected in $15-30 \%$ of hysterectomy specimens. It is characterized by the presence of endometrial glands and stroma within the myometrium. ${ }^{1}$ This disorder is seen primarily in reproductive age group and presents with dysmenorrhea, abnormal uterine bleeding, chronic pelvic pain and deep dyspareunia. However, adenomyosis is often an incidental finding in specimens obtained from hysterectomy or uterine biopsies. Women with adenomyosis also have other associated gynecologic conditions such as endometriosis or leiomyomas. ${ }^{2}$

The recent evolution of diagnostic imaging techniques such as transvaginal sonography, hysterosalpingography and magnetic resonance imaging has contributed to improve the accuracy in identifying this pathology. Hysteroscopy offers the advantage of direct visualization of the uterine cavity while giving the option of collecting histological biopsy samples under visual control. ${ }^{3}$ Traditionally, adenomyosis was only diagnosed after hysterectomy. However, studies have shown that a diagnosis can be made with biopsies at hysteroscopy and laparoscopy. ${ }^{2}$ But still the histopathogical examination of hysterectomy specimen provides the definite diagnosis and is considered the gold standard.

The exact aetiopathogenesis of adenomyosis has not been explained but two main theories may explain its pathogenesis: adenomyosis may arise from invagination of the myometrial basalis into the myometrium or an alternative theory explains that it may result from metaplasia of displaced embryonic pluripotent müllerian remnants or differentiation of adult stem cells. ${ }^{4}$ The data regarding incidence or incidental finding of adenomyosis in hysterectomy specimen is lacking despite this condition being common and bearing serious implications in symptomatology as well as in infertility. ${ }^{5}$

Hysterectomy is a procedure of removal of uterus with or without removal of its adnexa. Uterine, cervical, ovarian pathology or diseases of fallopian tubes are the main reason for its removal. Adenomyosis is also one of the causes of hysterectomy when diagnosed preoperatively. Adenomyosis can be incidental finding in hysterectomy done for other gynecologic pathology as well. Hence, this study has established the prevalence of adenomyosis as well as it's association with other uterine pathology in routine hysterectomy specimens.

\section{MATERIALS AND METHODS}

This was a cross sectional study conducted at Nepal Medical College and Teaching Hospital (NMCTH), Attarkhel, Gokarneshwor-8 Kathmandu for duration of one year (March 2019 to February 2020). All hysterectomy specimens (Total abdominal, vaginal and subtotal hysterectomies) operated at NMCTH were included in the study. However, endometrial biopsy and polypectomy cases were excluded. The gross examination was done following standard protocol for hysterectomy specimen. The gross findings suggestive of adenomyosis were noted as i) trabeculated areas in the myometrium, ii) hemorrhagic foci in myometrium and iii) minute cyst formation in the myometrium. ${ }^{6}$ Other gross abnormalities were also noted. Sections from endometrium and myometrium as well as from other parts were taken. The grossed sections were processed using tissue processor (Yorko). Next day routine embedding, cutting followed by staining of the prepared slides with Hematoxylin and Eosin was done. The prepared slides were examined under binocular microscope (Nikon Eclipse E200).

The slides were examined for the presence of endometrial glands and its stroma embedded deep in the myom etrium (at least one low power field away from endometrial and myometrial junction). ${ }^{7}$ The diagnosis was made only if the distance between the lower border of the endometrium and the adenomyosis exceeds one half of a low power field (approximately about $2.5 \mathrm{~mm})^{6}$ The glands could be in proliferative phase in first half of the cycle while the secretory change in the endometrium of adenomyosis could be absent or incomplete in the secretory phase. The endometrial stroma could be cellular or sparse with central pale area and a more dark staining peripheral cellular area. ${ }^{6}$

Other co-existent pathologic conditions of uterus were also noted down. Uterine, cervical, ovarian and tubal pathology were also observed. The obtained data was entered in Microsoft excel and results were obtained. Ethical clearance was taken from the Institutional Review Committee of NMCTH.

\section{RESULTS}

Total of 154 hysterectomies were received during the study period. There were 136 cases of total abdominal hysterectomies whereas 17 cases had undergone vaginal hysterectomy and one case was subtotal hysterectomy as 


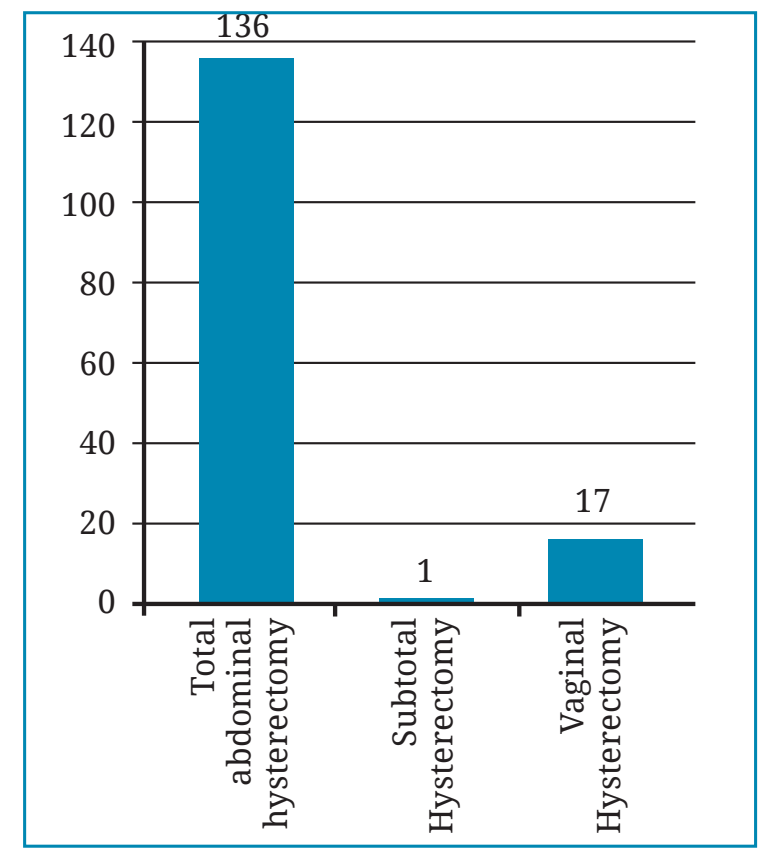

Fig. 1: Different types of hysterectomies.

shown in Fig. 1. Out of 154 hysterectomies, 37 cases showed adenomyosis. The prevalence of adenomyosis was $24 \%$.

Among the different types of hysterectomies, adenomyosis was seen in 37 cases. Out of which, 35 cases had undergone total abdominal hysterectomy and one each had vaginal and subtotal hysterectomy.

Distribution of adenomyosis among different types of hysterectomies are depicted in Table 1. The mean age for adenomyosis is $44 \pm 4.4$ years, with the median age of 45 years. The age group for adenomyosis ranged from 36 years to 52 years. Adenomyosis was most commonly seen in the age group of 35-40 years followed by 4650 years (Table 2 ).

Table 1: Adenomyosis in different types of hysterectomies

$\begin{array}{lcc}\begin{array}{l}\text { Hysterectomy } \\ \text { cases }\end{array} & \begin{array}{c}\text { With } \\ \text { adenomyosis } \\ \text { (n; \%) }\end{array} & \begin{array}{c}\text { Without } \\ \text { adenomyosis } \\ \text { (n; \%) }\end{array}\end{array}$

Total

abdominal

35 (23)

$101(65)$

hysterectomy

\begin{tabular}{lcc}
$\begin{array}{l}\text { Vaginal } \\
\text { hysterectomy }\end{array}$ & $1(1)$ & $16(10)$ \\
$\begin{array}{l}\text { Subtotal } \\
\text { hysterectomy }\end{array}$ & $1(1)$ & 0 \\
Total & $\mathbf{3 7 ( 2 5 )}$ & $\mathbf{1 1 7 ( 7 5 )}$ \\
\hline
\end{tabular}

Table 2: Age distribution among the adenomyosis cases

\begin{tabular}{|lcc|}
\hline Age group (years) & $\mathbf{n}$ & $\mathbf{\%}$ \\
$35-40$ & 13 & 35 \\
$41-45$ & 10 & 27 \\
$46-50$ & 12 & 32 \\
$51-55$ & 2 & 6 \\
Total & $\mathbf{3 7}$ & $\mathbf{1 0 0}$ \\
\hline
\end{tabular}

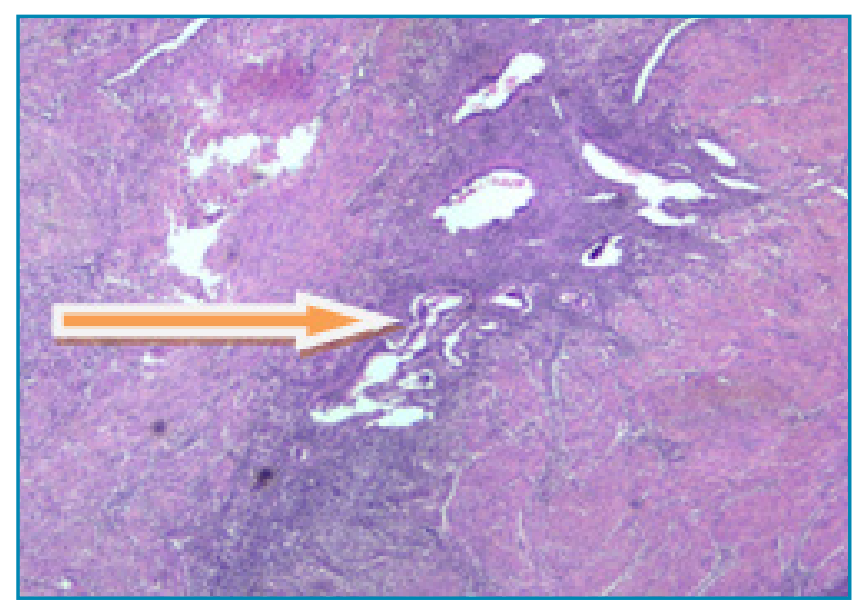

Fig. 2a: Showing presence of endometrial glands and stroma embedded deep within the myometrium (H \& E stain; 20x)

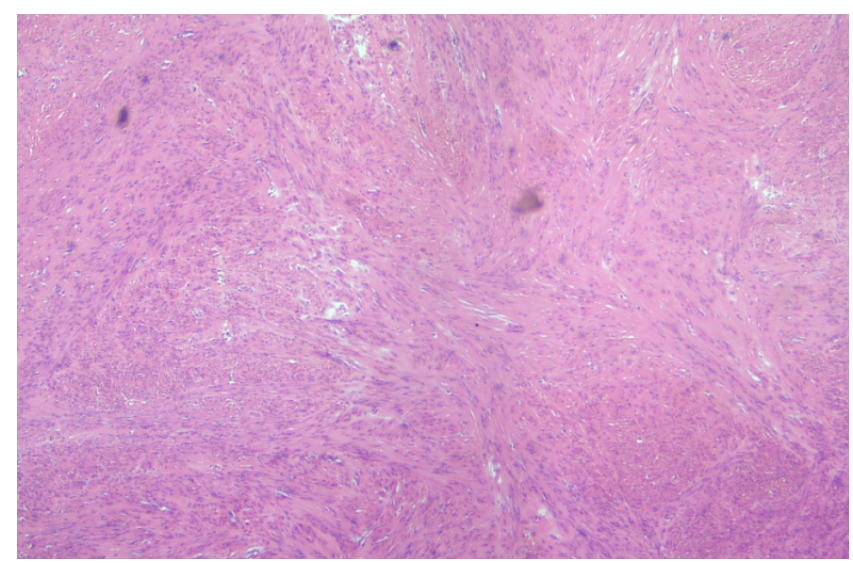

Fig. 2b: Showing microscopic picture of benign muscle bundles of leiomyoma ( $\mathrm{H} \& \mathrm{E}$ stain; 20x).

The most common pathology other than adenomyosis was leiomyoma. Out of the 37 cases of adenomyosis (Fig. 2a), 19 cases had co-existent leiomyoma (Fig. 2b) whereas 7 cases had other pathologies like 2 cases with endometriotic cyst, 2 cases of endometrial polyp 1 case of high grade squamous intraepithelial lesion (HSIL), one case of hyperplasia of 
endometrium with atypia and one case of serous cystadenoma of ovary.

Association of different types of gynecologic pathologies in association with adenomyosis is shown in Fig. 3.

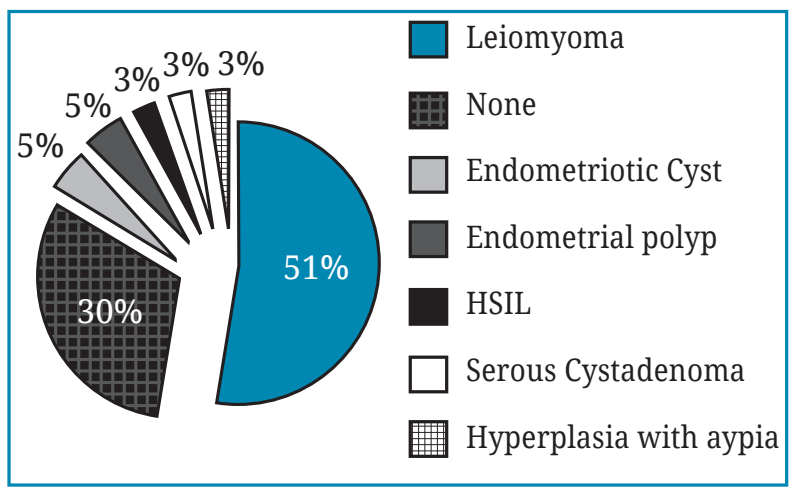

Fig. 3: Adenomyosis associated with different pathologies

\section{DISCUSSION}

Adenomyosis, a non- malignant condition of the uterus, is characterized by the presence of endometrial glands as well as stromal elements situated at least $2.5 \mathrm{~mm}$ below the endomyometrial junction..$^{8,9}$ This is a common condition detected in $15-30 \%$ of hysterectomy specimens. ${ }^{1}$

Total of 154 hysterectomies were received during the study period. Out of 154 cases, 136 cases were total abdominal hysterectomies whereas 17 cases had undergone vaginal hysterectomy and one case was subtotal hysterectomy. The number of total abdominal hysterectomies were greater than vaginal hysterectomy (in a ratio of 8:1) which is similar to a study done by Prevez et al ${ }^{10}$ where out of 861 hysterectomies, 779 were abdominal and remaining 82 were vaginal (in a ratio of 9.5:1).

The age group for adenomyosis ranged from 36-52 years with mean age of $44 \pm 4.4$ which is almost similar to the mean age in a study done by Tahlan et al ${ }^{9}$, Yu et al ${ }^{11}$ and Taran et al $^{12}$.

Out of 154 cases of hysterectomies, 37 cases showed adenomyosis (24\%) which is similar to a study done in Nepal by Shrestha et al ${ }^{8}$ in which adenomyosis was seen in 60 of 256 cases (23.4\%). The prevalence of adenomyosis between different studies have been compared in the following chart.

The chart comparing the prevalence of adenomyosis in different studies.

\begin{tabular}{|lcc|} 
Authors & $\begin{array}{c}\text { Place of } \\
\text { study }\end{array}$ & $\begin{array}{c}\text { Prevalence } \\
\%\end{array}$ \\
\hline Puente et $a l^{13} ; 2016$ & Spain & 24.4 \\
Vercellini et $a l^{14} ; 1995$ & Italy & 24.9 \\
Parazzini et $a l^{15} ; 2009$ & Italy & 28.2 \\
Naftalin et $a l^{16} ; 2012$ & United & 20.9 \\
Ki Donato et $a l^{17} ; 2014$ & Italy & 21.8 \\
Present study $; 2020$ & Nepal & 24.0 \\
\hline
\end{tabular}

A study done by Morassutto et al ${ }^{5}$ stated that adenomyosis was more prevalent after the age of 50 years. Another study by Rizvi et $a l^{18}$ concluded that perimenopausal age group (4050 years) was the most commonly affected group. The age group in these studies are almost similar to the age group affected by adenomyosis in the present study. The present study showed that $35 \%$ of affected patients were of age group 35- 40 years followed by 4650 years age group.

The most frequent co-pathology existing with adenomyosis was leiomyoma which accounted for 19 cases (51\%) followed by endometriotic cyst (5\%), endometrial polyp (5\%), HSIL (3\%), hyperplasia of endometrium with atypia (3\%), and serous cystadenoma (3\%). The similar pattern of combination pathologies was seen in other studies done by Naphatthalung et $a l^{19}$, Sawke et $a l,,^{20}$ Pervez et $a l^{10}$ and Vavilis et al. ${ }^{21}$

Leiomyoma was seen in 19 cases (51\%) in this study. Pervez et $a l^{10}$ also showed that leiomyoma accounted for $50.6 \%$ concluding that leiomyoma was the most common copathology seen in hysterectomy specimens. Our study showed that endometrial polyp (5\%) and endometrial hyperplasia (3\%) were rare co-existing pathologies. Pervez et $a l^{10}$ also stated that endometrial polyp hyperplasia were rare occurrence accounting for $5.4 \%$ and $1.6 \%$ respectively.

In conclusion, adenomyosis is quite common in our part of the world with prevalence of $24 \%$. The most common age group affected by adenomyosis was 35-50 years. The most frequent combination of co-pathology in cases of adenomyosis was leiomyoma.

\section{ACKNOWLEDGEMENT}

I would like to thank all the colleagues from Department of Pathology as well from the Department of Gynecology for their help during the study period. 


\section{REFERENCES}

1. Seidman JD, Kjerrulff KH. Pathologic findings from the Maryland women's health study: practice patterns in the diagnosis of adenomyosis. Int'l J Gynecol Pathol 1996; 15: 217-21.

2. Struble J, Reid S, Bedaiwy MA. Adenomyosis: A clinical review of a challenging gynecologic condition. J Min Inv Gynecol 2016; 23: 164-85.

3. Di Spiezio Sardo A, Calagna G, Santangelo F et al. The role of hysteroscopy in the diagnosis and treatment of adenomyosis. Biomed Res Int'l 2017; 2017: 1-7.

4. Donnez J, Donnez O, Dolmans MM. Introduction: uterine adenomyosis, another enigmatic disease of our time. Fertil Steril 2018; 109: 369-70.

5. Morassutto C, Monasta L, Ricci G, Barbone F, Ronfani L. Incidence and estimated prevalence of endometriosis and adenomyosis in Northeast Italy: A data linkage study. PLoS One 2016; 11: e0154227.

6. Kurman RJ, Ellenson LH, Ronnett BM, editors. Blaustein's pathology of the female genital tract $\left(6^{\text {th }}\right.$ ed). Springer 2011.

7. Rosai J, editor. Rosai and Ackerman's surgical pathology ( $9^{\text {th }}$ ed). Elsevier 2005.

8. Shrestha A, Shrestha R, Sedhai LB, Pandit U. Adenomyosis at hysterectomy: prevalence, patient characteristics, clinical profile and histopathological findings. Kathmandu Univ Med J 2012; 37: 53-6.

9. Tahlan A, Nanda A, Mohan H. Uterine Adenomyoma: A Clinicopathologic Review of 26 Cases and a Review of the Literature. Int'l J Gynecol Pathol 2006; 25: 361-5.

10. Pervez SN, Javed K. Adenomyosis among samples from hysterectomy due to abnormal uterine bleeding. J Ayub Med Coll Abbottabad 2013; 25: 68-70.

11. Yu O, Schulze-Rath R, Grafton J, Hansen K, Scholes $\mathrm{D}$, Reed SD. Adenomyosis incidence, prevalence and treatment: United States population-based study 2006-2015. Am J Obstet Gynecol 2020; 223: 94.e1-10.

12. Taran FA, Stewart EA, Brucker S. Adenomyosis: Epidemiology, Risk Factors, Clinical Phenotype and Surgical and Interventional Alternatives to Hysterectomy. Geburtshilfe Frauenheilkd 2013; 73: 924-31.
13. Puente JM, Fabris A, Patel J et al. Adenomyosis in Infertile Women: Prevalence and the Role of 3D Ultrasound as a Marker of Severity of the Disease. Reprod Biol Endocrinol 2016; 14: 60.

14. Vercellini P, Parazzini F, Oldani S, Panazza S, Bramante T, Crosignani PG. Adenomyosis at hysterectomy: a study on frequency distribution and patient characteristics. Hum Reprod 1995; 10: $1160-2$.

15. Parazzini F, Mais V, Cipriani S, Busacca M, Venturini P. Determinants of adenomyosis in women who underwent hysterectomy for benign gynecological conditions: results from a prospective multicentric study in Italy. Eur J Obstet Gynecol Reprod Biol 2009; 143: 103-6.

16. Naftalin J, Hoo W, Pateman K, Mavrelos D, Holland T, Jurkovic D. How common is adenomyosis? A prospective study of prevalence using transvaginal ultrasound in a gynaecology clinic. Hum Reprod 2012; 27: 3432-39.

17. Di Donato N, Montanari G, Benfenati A et al. Prevalence of Adenomyosis in Women Undergoing Surgery for Endometriosis. Eur $J$ Obstet Gynecol Reprod Biol 2014; 181: 289-93.

18. Rizvi G, Pandey H, Pant H, Chufal SS, Pant P. Histopathological correlation of adenomyosis and leiomyoma in hysterectomy specimens as the cause of abnormal uterine bleeding in women in different age groups in the Kumaon region: A retroprospective study. J Midlife Health 2013; 4: 27-30.

19. Naphatthalung W, Cheewadhanaraks S. Prevalence of endometriosis among patients with adenomyosis and/or myoma uteri scheduled for a hysterectomy. J Med Assoc Thai 2012; 95: 1136-40.

20. Sawke NG, Sawke GK, Jain H. Histopathology findings in patients presenting with menorrhagia: A study of 100 hysterectomy specimen. J Midlife Health 2015; 6: 160-3.

21. Vavilis $\mathrm{D}$, Agorastos $\mathrm{T}$, Tzafetas $\mathrm{J}$ et al. Adenomyosis at hysterectomy: prevalence and relationship to operative findings and reproductive and menstrual factors. Clin Exp Obstet Gynecol 1997; 24: 36-38. 